\title{
INVENTARIO DE MALESTAR PERCIBIDO POR INESTABILIDAD LABORAL (IMPIL)
}

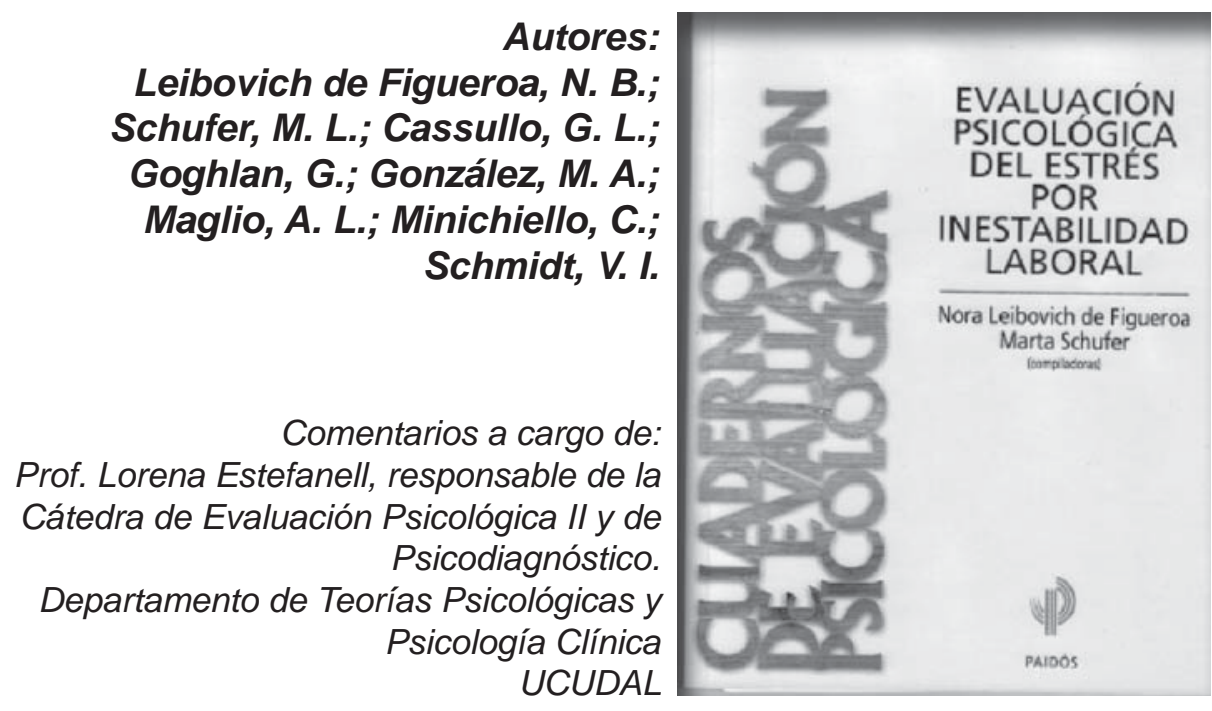

Ficha Técnica

\begin{tabular}{|l|l|}
\hline Nombre: & $\begin{array}{l}\text { Inventario de malestar percibido por inestabilidad la- } \\
\text { boral (IMPIL) }\end{array}$ \\
\hline Autores: & $\begin{array}{l}\text { Nora B Leibovich de Figueroa; Marta Schufer; Gabriela } \\
\text { Livia Cassullo; Gabriel Goghlan; Maria Alejandra } \\
\text { Gonzalez; Ana Laura Maglio; Claudia Minichiello; } \\
\text { Vanina Schmidt. }\end{array}$ \\
\hline Editorial: & Paidós \\
\hline $\begin{array}{l}\text { Ámbito de } \\
\text { aplicación: }\end{array}$ & Área laboral, organizacional, clínica \\
\hline
\end{tabular}

El desarrollo de la técnica corresponde a una necesidad de alertar sobre el fenómeno del estrés y vincularlo a una variable psicosocial de gran relevancia como es la inestabilidad laboral. Investigaciones recientes (Juárez, 2000) han identificado la "inseguridad laboral" como uno de los mayores riesgos psicosociales vinculados al estrés laboral en Latinoamérica, siendo en muchos casos la principal causa de estrés en los trabajadores.

El Inventario de malestar percibido por inestabilidad laboral (IMPIL) surge del trabajo de varios investigadores argentinos -de reconocida trayectoria-, como una respuesta a contextos económicos cambiantes e inestables y busca evaluar el estrés psicológico que genera en el individuo esta variable. 
Para la construcción del inventario se realizaron entrevistas con informantes claves, expertos en el tema y actores principales (trabajadores en relación de dependencia, ambos sexos).

A partir del análisis de un estudio piloto con una muestra compuesta por trabajadores en relación de dependencia, se seleccionaron los ítems con una frecuencia superior al 30\%. El instrumento quedó así estructurado con 101 ítems, los que se agruparon en 8 categorías que miden el impacto del estrés generado por la inestabilidad laboral. De acuerdo a un criterio racional se agruparon los ítems en 8 categorías que miden el impacto del estrés generado por la inestabilidad laboral. En la determinación del coeficiente de confiabilidad (alfa de Cronbach) los valores oscilaron entre 0.60 y 0.94 .

Estas escalas son:

- Problemas interpersonales: Esta escala está compuesta por 10 ítems y evalúa el impacto de los sucesos provenientes del contexto interpersonal que son percibidos como malestar.

- Competencia personal: Esta escala esta compuesta por 21 ítems y evalúa el impacto que generan los sucesos provenientes de la valoración de los demás, en relación con el desempeño personal que son percibidos como malestar.

- Preocupaciones por la salud: Esta escala esta compuesta por 6 ítems y evalúa el impacto de los síntomas psicofísicos, provenientes del trabajo, que son percibidos como malestar.

- Molestias medio- ambientales: Esta escala esta compuesta por 11 ítems y evalúa el impacto de los sucesos provenientes de los ingresos y egresos económicos, en relación con el área de trabajo, que son percibidos como malestar.

- Preocupaciones económicas: Esta escala esta compuesta por 19 ítems y evalúa el impacto de los sucesos provenientes de los ingresos y egresos económicos, relacionados con el trabajo, que son percibidos como malestar.

- Preocupaciones en relación al futuro: Esta escala esta compuesta por 5 ítems y evalúa el impacto de los pensamientos en relación con el futuro (próximo y lejano), relacionados con el trabajo, que son percibidos como malestar.

- Molestias emocionales: Esta escala esta compuesta por 21 ítems y evalúa el impacto de los sentimientos en relación con el trabajo actual (y la inseguridad laboral), que son percibidos como malestar.

- Molestias cognitivas: Esta escala esta compuesta por 15 ítems y evalúa el impacto de los pensamientos en relación con el trabajo (y la inestabilidad laboral), que son percibidos como malestar.

Cada subescala esta compuesta por diferente número de ítems, donde los trabajadores expresan el grado de malestar percibido según una escala con 5 opciones, donde 1 refiere a que "le sucede pero no le produce malestar" y 5 a "le causa pánico- miedo".

En la corrección se obtienen diferentes puntajes:

- Puntaje de sucesos: nos da la medida objetiva de la frecuencia en que ocurre el suceso que produce malestar. El puntaje se obtiene contando el número de sucesos que recibieron evaluación y que fueron marcados por el sujeto como generadores de malestar (puntuación mayor de 2).

- Puntaje de impacto: este puntaje sería el mejor indicador de la experiencia subjetiva de malestar. Se obtiene sumando el valor adjudicado a cada suceso (ítem) marcado.

- Relación impacto- suceso: este número nos indica la vulnerabilidad del sujeto a 
percibir malestar y se obtiene de la división del puntaje de impacto sobre el puntaje de suceso. Este puntaje se obtiene para cada sub- escala.

Para la conversión de los resultados obtenidos, existe una tabla que permite identificar el percentil al que se corresponden esos puntajes brutos. Esta distribución percentil permite comparar los puntajes del trabajador y ubicarlo en relación a la muestra original de 187 trabajadores de ambos sexos y en relación de dependencia.

El inventario es autoadministrado y se le solicita al encuestado que tome en cuenta los sucesos de los últimos 6 meses.

Este instrumento permite obtener puntuaciones que identifican, por un lado la cantidad de sucesos estresantes que percibe el trabajador -como consecuencia de insetablidad labora-l, el grado de impacto que estos sucesos tienen para el trabajador y la vulnerabilidad del mismo frente a los sucesos estresantes.

Con el IMPIL tenemos un instrumento que nos permite evaluar el impacto de un estresor puntual, como la inestabilidad laboral, tan frecuente en los actuales escenarios económicos. 